\title{
Profile of the elderly in physical therapy and its relation to functional disability
}

\author{
Perfil do idoso na fisioterapia e sua relação com a incapacidade funcional
}

Ana L. S. Rossi, Vanessa S. Pereira, Patrícia Driusso, José R. Rebelatto, Natalia A. Ricci

\begin{abstract}
Background: As the population ages, changes occur in the epidemiological profile towards the current predominance of chronic degenerative diseases which, when untreated, lead to loss of functional capacity and require long-term assistance. Objectives: To describe the profile of the elderly attending the geriatric physical therapy service and to identify factors associated with functional disability. Method: A cross-sectional descriptive analytical study was conducted. The medical records of elderly individuals were analyzed using the first physical therapy assessment, which included sociodemographic, clinical and mobility data. To determine the degree of disability (mild/moderate), the Brazilian Multidimensional Functional Assessment Questionnaire (BOMFAQ) was used. Descriptive analysis and univariate logistic regression were performed, followed by multivariate logistic regression. Results: The sample comprised 130 elderly patients with a mean age of 73.3 [standar deviation $(\mathrm{SD})=7.2$ ] years-old, predominantly female $(63.9 \%)$, sedentary $(71.5 \%)$ and presenting three to four diseases $(47.7 \%)$. The mean of activities with difficulty in the BOMFAQ was 6.7 ( $\mathrm{SD}=4.8), 35(26.9 \%)$ individuals presented mild disability and $95(73.1 \%)$ moderate. The participant characteristic that presented a greatest risk of disability was self-reporting of poor health $(\mathrm{OR}=12.4)$. The factors identified, which together can determine functional decline, were sedentary lifestyle, presence of dizziness, polypharmacy and high pain intensity. Conclusions: Elderly individuals attended by the geriatric physical therapy service showed a profile associated with disability, characterized by potentially modifiable factors. This profile also reinforces the demand for long-term care for this population.
\end{abstract}

Keywords: physical therapy; health services for the aged; aged; disabled health.

HOW TO CITE THIS ARTICLE

Rossi ALS, Pereira VS, Driusso P, Rebelatto JR, Ricci NA. Profile of the elderly in physical therapy and its relation to functional disability. Braz J Phys Ther. 2013 Jan-Feb; 17(1): 77-85. http://dx.doi.org/10.1590/S1413-35552012005000060

RESUMO | Contextualização: Com o envelhecimento populacional, houve alterações no perfil epidemiológico, com o predomínio atual das doenças crônico-degenerativas que, quando não tratadas, levam à perda da capacidade funcional e exigem assistência de longo prazo. Objetivos: Descrever o perfil do idoso atendido no serviço de fisioterapia geriátrica e identificar fatores associados à incapacidade funcional. Método: Foi realizado estudo transversal descritivo analítico. Os prontuários dos idosos foram analisados por meio da primeira avaliação fisioterapêutica, que incluiu dados sociodemográficos, clínicos e de mobilidade. Para determinar o grau de deficiência (leve/ moderada), foi aplicado o Brazilian Multidimensional Functional Assessment Questionnaire (BOMFAQ). A análise descritiva e a regressão logística univariada foram realizadas, seguidas de regressão logística multivariada. Resultados: A amostra foi composta por 130 pacientes idosos, com mais de 73,3 7,2 anos de idade, predominantemente do sexo feminino $(63,9 \%)$, sedentários $(71,5 \%)$ e apresentando de três a quatro doenças $(47,7 \%)$. A média de atividades com dificuldade no BOMFAQ foi de $6,7 \pm 4,8$; $35(26,9 \%)$ indivíduos apresentaram incapacidade leve e 95 (73,1\%), moderada. A característica que apresentou maior risco de incapacidade foi o autorrelato de saúde ruim $(\mathrm{OR}=12,4)$. Os fatores identificados, que juntos podem determinar o declínio funcional, foram sedentarismo, presença de tontura, polifarmácia e alta intensidade da dor. Conclusões: Os idosos atendidos pelo serviço de fisioterapia geriátrica mostraram um perfil associado com deficiência, caracterizada por fatores potencialmente modificáveis. Esse perfil também reforça a demanda por cuidados de longa duração para essa população.

Palavras-chave: fisioterapia; serviço de saúde para idosos; idade; incapacidade. 


\section{Introduction}

As the population ages, changes occur in the epidemiological profile, towards the current predominance of chronic degenerative diseases ${ }^{1}$ which, when untreated, lead to loss of functional capacity and require long-term assistance ${ }^{2,3}$.

Functional capacity and independence imply the ability to perform activities of daily living (ADL), instrumental activities of daily living (IADL) and mobility tasks ${ }^{2}$. Their loss causes the elderly to become totally or partially dependent, which negatively affects their quality of life $e^{1,2,4}$. In studies concerning the degree of functional loss ${ }^{5,6}$, elderly individuals independent in ADL represent about 50 to $84 \%$ of the elderly population, those with mild disability 8 to $33 \%$, while those with severe disability represents 8 to $15 \%$.

Chronic degenerative diseases associated with disabilities that accompany senile aging require a significant and growing demand for healthcare services. Among the various forms of assistance that possess a direct relation with functionality and mobility is rehabilitation/physical therapy ${ }^{3}$. In populations with disabling conditions, the rates of use of rehabilitation services represent about $47 \%$ of all medical expenses and physical therapy is the most widely used ${ }^{7}$. In China, physical therapy is the Western treatment prescribed in $62.5 \%$ of cases of patients in rehabilitation ${ }^{8}$.

In physical therapy, the elderly are often attended in diverse areas, including rheumatology, neurology, cardiology and respiratory function. Thus, they are attended without the specificity required for geriatric consultation. In a population-based study that investigated the use of physical therapy services for adults and the elderly in Brazil, the prevalence of the use of this therapeutic modality at least once in a patient's lifetime was $30.2 \%$ and the use in the 12 months preceding the survey was $4.9 \%{ }^{9}$. The demand for physical therapy services occurred in $34.8 \%$ of cases involving back problems, $16.9 \%$ for trauma, sprains and muscle injuries and $8.4 \%$ for rheumatic problems ${ }^{9,10}$. Of the individuals who were referred to physical therapy, $66 \%$ used public services and in relation to consultations in the preceding year, most of the patients were women and elderly ${ }^{9}$.

Given the growing elderly population and the fact that physical therapy is often incorporated into the treatment of this population, it is important to know the clientele of geriatric physical therapy to program a better treatment, with appropriate management and for adequate periods, in order to reduce overall healthcare costs, while diminishing dependency and disability and improving quality of life for this population'.
The purpose of this study was to outline the profile of the elderly attended by the geriatric physical therapy service of a rehabilitation center and determine the factors associated with functional disability.

\section{Method}

A cross-sectional, quantitative, descriptive, analytical study was conducted. This study was approved by the Research Ethics Committee of the Universidade Federal de São Carlos (UFSCar), São Carlos, SP, Brazil, protocol number 497/2009.

The sample consisted of elderly individuals treated by the geriatric physical therapy service of a public rehabilitation center. The medical records of patients referred to this service were analyzed to collect data related to the initial physical therapy evaluation. This constitutes a standardized assessment conducted following the admission of elderly individuals to geriatric physical therapy, which is performed to elaborate treatment management.

Admission to the service includes: age of 60 yearsold or over, no requirement for artificial respiration or any type of life-maintaining device and medical referral for physical therapy. Medical records of elderly individuals that did not contain all the data needed to conduct this study were excluded, together with those who refused to sign the consent form.

The medical records of elderly patients were analyzed by means of standardized physical therapy assessment data. The evaluation was conducted in an interview involving open questions to the patient and, whenever necessary, their caregiver. This assessment included sociodemographic, functional and physical/ clinical data and tests specific to physical therapy. Sociodemographic data were obtained through a structured questionnaire including the variables such as, gender, age (years), educational level and marital status.

Among the clinical data, dichotomous questions (yes/no) were posed regarding the needs of caregivers, hospitalization in the preceding year, use of assistive devices for walking, history of falls in the preceding six months and the presence of dizziness. Regarding lifestyle habits, questions were asked about smoking (smoker, former smoker and never smoked), alcohol consumption (alcoholic, ex-alcoholic and never drank) and physical activity (yes/no). Possible diagnoses and medications used were obtained by patient selfreporting. Diseases reported that were investigated included: diabetes mellitus, cardiovascular disease, osteoarthritis/arthrosis, osteoporosis, hipertension, stroke, lung disease, depression, labyrinthitis and dementia. A subjective assessment of general health, vision and hearing was performed, categorized as: 
excellent, very good, good, poor and very poor. Due to the small number of responses in the categories "excellent" and "very poor" they were combined with the categories "good" and "poor", respectively. With regards to cognition, data was collected following observation by the physical therapist and categorized as: oriented, confused/obeys commands, disoriented/does not obey simple commands, and uncommunicative. Given the inclusion criteria for the service, very few cases fit in the "disoriented" and "uncommunicative" categories, so these were combined in the category "confused".

To evaluate mobility, the "Timed Up and Go" (TUG) test was used. The TUG quantifies functional mobility by measuring the time taken to perform the task of rise from a chair, walk a distance of 3 meters, turn around, return to the chair and sit down ${ }^{11}$. In the test, the use of assistive devices for walking by the individual is permitted. In this study, the total time spent on complete the task was determined and a cutoff of 13.5 seconds was used to differentiate patients that presented a risk of falling from those that did not ${ }^{12}$.

Functional evaluation was performed using the Older Americans Resources and Services Program (OARS), a questionnaire developed by Duke University ${ }^{13}$, cross-culturally adapted and validated for Brazilian-Portuguese ${ }^{14}$. In the service's evaluation, only part of the OARS is used, that related to physical health, and is denominated the Brazilian Multidimensional Functional Assessment Questionnaire (BOMFAQ).

The BOMFAQ is a questionnaire comprising 15 questions concerning the degree of difficulty (none, moderate and severe) in performing ADL and IADL $^{15}$, which are answered during a structured interview by the patient or their caregiver. The classification of the questionnaire is determined by the sum of the activities that present moderate or severe difficulty. For this study, a cutoff of over four was used for moderate/total disability and below four for independence/slight disability ${ }^{16}$. Since few cases were categorized as no difficulty $(n=6)$, these were combined within the independence/slight disability category.

Complaints of pain were also included in the evaluation, together with their intensity, determined using the Visual Analogue Scale (VAS). The VAS consists of a straight $10 \mathrm{~cm}$ line on which the value of zero represents "no pain" and 10 represents the "worst pain possible". The elderly individual was asked to mark on the line the place that represented the intensity of their pain within the preceding 24 hours. The distance in centimeters between the zero and the mark made by the patient, corresponds to the intensity of the pain ${ }^{17}$. To locate the areas of pain, a body chart was used. This consists of a drawing of the human body on which the patient marks the painful $\operatorname{area}(s)^{18}$. In this study, the painful areas marked on the diagram were categorized as the spine, upper limbs and lower limbs.

The physical therapy assessment also includes data concerning muscle strength, range of motion and gait analysis, among other factors. However, these data are evaluated according to the functional needs of the patient and thus, vary widely regarding their acquisition and registration, which is why they were not used in this study.

Only medical records of patients whose evaluations occurred between January and December 2008 were analyzed. This period was chosen to show the profile of the elderly over one year of care, following the introduction of standardized assessment in the geriatric physical therapy service.

\section{Statistical analysis}

To characterize the profile of the elderly descriptive analyses were performed for all variables for the whole sample and its division into BOMFAQ slight ( $<4$ activities with difficulty) and moderate ( $\geq 4$ activities with difficulty). In order to verify which independent variables were associated with functional disability (dependent variable), univariate logistic regression analysis was performed, adjusted for age. The independent variables that were included in the univariate regression model were those considered statistically significant $(\mathrm{p}<0.05)$ in the association tests $(\chi$ and Student's t test for independent samples). Multivariate logistic regression analysis, through the stepwise model, was performed for independent variables that were significant $(\mathrm{p}<0.05)$ in the univariate regression. Statistical analysis was performed using the Statistical Package for the Social Sciences, SPSS version 10.0, with a significance level of $5 \%$.

\section{Results}

A total of 140 patients were attended in the geriatric physical therapy service during the study period and, of these, 130 elderly individuals met the study inclusion criteria. The remaining 10 patients were excluded due to lack of clinical/medical data.

The final sample consisted of 130 elderly individuals, with a mean age of 73.3 [standard deviation $(\mathrm{SD})=7.2$ ] years-old, with 40 patients $(30.8 \%)$ aged 60 to 69 years-old, $62(47.7 \%)$ aged 70 and 79 years-old and $28(21.5 \%)$ aged 80 yearsold or over. The profile of the elderly individuals receiving physical therapy was predominantly female $(63.9 \%)$, married $(57.4 \%)$, low educational 
Table 1. Characterization of the profile of elderly individuals assisted by physical therapy.

\begin{tabular}{|c|c|c|c|}
\hline Variable & $\begin{array}{l}\text { Total } \\
\text { n }(\%)\end{array}$ & $\begin{array}{c}\text { BOMFAQ (0-3) } \\
\text { n (\%) }\end{array}$ & $\begin{array}{c}\text { BOMFAQ }(>4) \\
\text { n }(\%)\end{array}$ \\
\hline Age $($ mean $\pm S D)$ & $73.3 \pm 7.3$ & $70.3 \pm 6.23$ & $74.3 \pm 7.3$ \\
\hline \multicolumn{4}{|l|}{ Gender $(n=130)$} \\
\hline Female & $83(63.8)$ & $17(48.6)$ & $66(69.5)^{*}$ \\
\hline Male & $47(36.1)$ & $18(51.4)$ & $29(30.5)$ \\
\hline \multicolumn{4}{|l|}{ Marital status $(n=129)$} \\
\hline Single & $14(10.8)$ & $3(8.6)$ & $11(11.7)$ \\
\hline Married & $74(57.4)$ & $25(71.4)$ & $49(52.1)$ \\
\hline Widow & $41(31.8)$ & $7(20.0)$ & $34(36.2)$ \\
\hline \multicolumn{4}{|l|}{ Education level $(\mathrm{n}=126)$} \\
\hline Illiterate & $23(18.2)$ & $6(17.6)$ & $17(18.5)$ \\
\hline Elementary school & $53(42.1)$ & $9(26.5)$ & $44(47.8)$ \\
\hline Midle school & $16(12.7)$ & $4(11.8)$ & $12(13.0)$ \\
\hline High school & $11(8.7)$ & $5(14.7)$ & $6(6.5)$ \\
\hline Undergraduate & $23(18.3)$ & $10(29.4)$ & $13(14.2)$ \\
\hline \multicolumn{4}{|l|}{ Caregiver $(\mathrm{n}=130)$} \\
\hline Yes & $41(31.5)$ & $5(14.3)$ & $36(37.9)^{*}$ \\
\hline No & $89(68.5)$ & $30(85.7)$ & $59(62.1)$ \\
\hline \multicolumn{4}{|l|}{ Hospitalization $(n=130)$} \\
\hline Yes & $38(29.2)$ & $8(22.9)$ & $30(31.6)$ \\
\hline No & $92(70.8)$ & $27(77.1)$ & $65(68.4)$ \\
\hline \multicolumn{4}{|l|}{ General Health $(n=127)$} \\
\hline Excellent & $16(12.6)$ & $9(26.5)$ & $7(7.5)^{*}$ \\
\hline Good & $82(64.6)$ & $22(64.7)$ & $60(64.6)$ \\
\hline Poor & $29(22.8)$ & $3(8.8)$ & $26(27.9)$ \\
\hline \multicolumn{4}{|l|}{ Vision $(\mathrm{n}=127)$} \\
\hline Excellent & $18(14.2)$ & $8(23.5)$ & $10(10.7)^{*}$ \\
\hline Good & $75(59.1)$ & $21(61.8)$ & $54(58.1)$ \\
\hline Poor & $34(26.7)$ & $5(14.7)$ & $29(31.2)$ \\
\hline \multicolumn{4}{|l|}{ Hear $(n=127)$} \\
\hline Excellent & $36(28.3)$ & $10(29.4)$ & $26(28.0)^{*}$ \\
\hline Good & $69(54.3)$ & $22(65.7)$ & $47(50.5)$ \\
\hline Poor & $22(17.4)$ & $2(5.8)$ & $20(21.5)$ \\
\hline Number of diseases $($ mean \pm SD) & $3.6 \pm 1.5$ & $2.9 \pm 1.4$ & $3.9 \pm 1.5^{* *}$ \\
\hline \multicolumn{4}{|l|}{ Comorbidities $(\mathrm{n}=130)$} \\
\hline None & - & & \\
\hline $1-2$ diseases & $31(23.8)$ & $17(48.6)$ & $14(14.7)^{*}$ \\
\hline $3-4$ diseases & $62(47.7)$ & $13(37.1)$ & $49(51.6)$ \\
\hline$>5$ diseases & $37(28.5)$ & $5(14.3)$ & $32(33.7)$ \\
\hline \multicolumn{4}{|l|}{ Osteathritis $(\mathrm{n}=130)$} \\
\hline Yes & $65(50.0)$ & $15(42.9)$ & $50(52.6)$ \\
\hline No & $65(50.0)$ & $20(57.1)$ & $45(47.4)$ \\
\hline \multicolumn{4}{|l|}{ Osteoporosis $(\mathrm{n}=130)$} \\
\hline Yes & $21(16.1)$ & $3(8.6)$ & $18(18.8)$ \\
\hline No & $109(83.9)$ & $32(91.4)$ & $77(81.2)$ \\
\hline \multicolumn{4}{|l|}{ Hypertension $(n=130)$} \\
\hline Yes & $90(69.2)$ & $20(57.1)$ & $70(73.7)^{*}$ \\
\hline No & $40(30.8)$ & $15(42.9)$ & $25(26.3)$ \\
\hline \multicolumn{4}{|l|}{ Stroke $(n=130)$} \\
\hline Yes & $18(13.8)$ & $2(5.7)$ & $16(16.8)^{*}$ \\
\hline No & $112(86.2)$ & $33(94.3)$ & $79(83.2)$ \\
\hline \multicolumn{4}{|l|}{ Diabetes $(n=130)$} \\
\hline Yes & $28(21.5)$ & $3(8.6)$ & $25(26.3)^{*}$ \\
\hline
\end{tabular}

TUG=Time Up and Go; VAS=Visual Analogue Scale. *p $<0.05$ for Chi-square; **p $<0.05$ for Student's $\mathrm{t}$ test for independent samples. 
Table 1. Continuation...

\section{Variable}

No

Depression $(\mathrm{n}=130)$

Yes

No

Labyrinthitis $(\mathrm{n}=130)$

Yes

No

Demencia $(n=130)$

Yes

No

Cardiovascular disease $(n=130)$

Yes

No

Lung disease $(\mathrm{n}=130)$

Yes

No

Medication (mean \pm SD)

Smoking $(n=130)$

Smoker

Ex-smoker

Never smoked

Alcoholism $(n=130)$

Alcoholic

Ex-alcoholic

Never drank

Physical activity $(\mathrm{n}=130)$

Yes

No

Falls $(\mathrm{n}=130)$

Yes

No

Dizziness $(\mathrm{n}=130)$

Yes

No

Cognition ( $\mathrm{n}=130)$

Oriented

Confused

Assistive devices $(n=130)$

Yes

No

TUG (mean \pm SD)

VAS (mean \pm SD)

Back pain $(n=111)$

Yes

No

Upper limbs pain $(n=111)$

Yes

No

Lower limbs pain $(n=111)$

\section{Total}

n $(\%)$

$102(78.5)$

$20(15.4)$

$110(84.6)$

$13(10.0)$

117(90.0)

$9(6.9)$

$121(93.1)$

$31(23.8)$

99 (76.2)

$9(7.0)$

$121(93.0)$

$3.9 \pm 2.8$

$10(7.7)$

29 (22.3)

$91(70.0)$

$14(10.8)$

13 (10.0)

103 (79.2)

37 (28.5)

93 (71.5)

$50(38.5)$

$80(61.5)$

49 (37.7)

81 (62.3)

109 (83.8)

$21(16.2)$

37 (28.5)

93 (71.5)

$19.8 \pm 12.5$

$6.6 \pm 2.6$

65 (58.6)

46 (41.4)

55 (49.5)

56 (50.5)

$93(83.8)$

$18(16.2)$

BOMFAQ (0-3)
n (\%)
$32(91.4)$

1 (2.9)

34 (97.1)

2 (5.7)

33 (94.3)

1 (2.9)

34 (97.1)

6 (17.1)

29 (82.9)

0

35 (100)

$2.7 \pm 2.2$

3(74.3)

10(14.3)

22 (11.4)

5 (8.6)

4 (28.6)

26 (62.9)

$20(57.1)$

15 (42.9)

9 (25.7)

26 (74.3)

5 (14.3)

30 (85.7)

34 (97.1)

1 (2.9)

3 (8.6)

32 (91.4)

$13.3 \pm 4.8$

$5.2 \pm 1.0$

$18(58.1)$

13 (41.9)

14 (45.2)

17 (54.8)

21 (67.7)

$10(32.3)$
BOMFAQ (>4)

n $(\%)$

70 (73.7)

$19(20.0)^{*}$

$76(80.0)$

11 (11.6)

84 (88.4)

8 (8.4)

87 (91.6)

25 (26.3)

$70(73.7)$

$9(9.5)$

$86(90.5)$

$4.4 \pm 2.9 * *$

07 (56.8)

19 (22.1)

69 (21.1)

9 (7.4)

9(20.0)

77(72.6)

$17(17.9)^{*}$

78 (82.1)

$41(43.2) *$

54 (56.8)

$44(46.3)^{*}$

$51(53.7)$

$75(78.9)^{*}$

20 (21.1)

$34(35.8)^{*}$

61 (64.2)

$22.7 \pm 13.8^{* *}$

$7.2 \pm 2.6 * *$

47 (58.8)

33 (41.2)

41 (51.3)

39 (48.7)

$72(90.0)^{*}$

TUG=Time Up and Go; VAS=Visual Analogue Scale. *p<0.05 for Chi-square; **p $<0.05$ for Student's t test for independent samples. 
level $(42.1 \%)$, non-smoker (70.0\%), non-alcoholic (79.2\%), sedentary (71.5\%) and who did not require caregivers $(68.5 \%)$. The elderly patients presented three to four diseases $(47.7 \%)$, the most prevalent were hypertension $(69.2 \%)$ and osteoarthritis $(50.0 \%)$.

Regarding mobility, 37 elderly patients (28.46\%) used assistive devices for walking and the mean time taken to complete the TUG was $19.8(\mathrm{SD}=12.6)$ seconds. Of the 126 elderly individuals who performed the TUG, $72(57.1 \%)$ required more than 13.5 seconds to performed the test, $36(28.6 \%)$ performed the test under 13.5 seconds and $18(14.3 \%)$ were unable to complete the test.

Among the 129 elderly individuals whose pain evaluation was registered on their medical records, $116(89.92 \%)$ complained of VAS pain intensity of $6.6(\mathrm{SD}=2.6) \mathrm{cm}$, while the site of the pain most often indicated on body chart was the lower limbs (93 cases, $83.8 \%$ ).

Regarding functional capacity according to the BOMFAQ, 35 elderly individuals (26.9\%) presented BOMFAQ slight and 95 (73.1\%), moderate. The total sample presented a mean of $6.7(\mathrm{SD}=4.8)$ in BOMFAQ activities with difficulty. The remaining characterization data are presented in Table 1.

The elderly individuals categorized as BOMFAQ moderate compared to those categorized as BOMFAQ slight were older, predominantly female, who used multiple medications, presented comorbidities, greater self-reporting of poor general health, hearing and vision, sedentarism, diabetes, dizziness, pain in the lower limbs and who used assistive devices for walking $(\mathrm{p}<0.05)$.

The characteristic that presented the greatest risk of disability was self-reporting of the patient's poor general health, representing a 12.4-fold probability of the elderly individual evolving from BOMFAQ slight to moderate. For each additional year of life, the probability of the elderly individual evolving to moderate dependency was $8.6 \%$. In the TUG test, every second longer corresponded to a $17.4 \%$ probability of evolving to BOMFAQ moderate. Other variables associated with disability and their relative risks are presented in Table 2.

Table 3 shows the combined variables that are associated with the impairment of functional capacity according to the BOMFAQ. Thus, the profile of elderly individuals at greater risk of becoming dependent are those who do not practice physical activity, complain of dizziness, use multiple medications and who report high pain intensity according to VAS.

\section{Discussion}

The elderly attended by the geriatric physical therapy service presented a profile associated with disability that was characterized by potentially modifiable factors, such as pain intensity, dizziness, polypharmacy and sedentary lifestyle. This profile further reinforces the demand for long-term care for this population.

In a French population study, $46.1 \%$ of the elderly presented mild disability, while $28.5 \%$ presented moderate to severe disability ${ }^{19}$. One study conducted in Brazil involving 33.786 elderly individuals verified that the most prevalent profile was healthy elderly individuals $(50.8 \%)$, followed by mild $(33.7 \%)$ and severe disability $(15.5 \%)^{6}$. Unlike epidemiological studies with community-dwelling elderly, the present study, involving patients at a rehabilitation center, showed a higher prevalence of moderate/ severe disability. These data reveal that the functional level of the elderly attended by the rehabilitation center is worse than that of the general population, which is probably the reason they were being treated with physical therapy.

Female gender and older age appear on a recurring basis as risk factors for functional disability in the majority of studies ${ }^{16,19,20}$ and the present study is no exception. Women have a higher life expectancy than men and pass a greater proportion of their life with functional disability; moreover, when affected by this condition, they live for a longer period with dependency ${ }^{21}$. Concerning old age, an exponential increase in the likelihood of the risk of disability occurs, from 1.86 between 65 and 69 years of age to 35.74 at 80 years of age and over ${ }^{16}$. As age increases, the proportion of years lived free from functional disability decreases ${ }^{21,22}$. The relation between age and functional disability is associated with the interaction between alterations resulting from aging and the presence of comorbidities.

The presence of at least one chronic disease increases with age $e^{23,24}$, with only $10 \%$ of individuals aged less than 20 years-old presenting chronic disease, while approximately $70 \%$ of those aged 70 years-old or over present at least one. As verified in this study, the presence of comorbidities is associated with disability, revealing the need to control and stabilize chronic diseases to prevent the progression of adverse effects.

Among the chronic diseases related to disability, diabetes mellitus, stroke and depression are highlighted in numerous studies ${ }^{19,20,25}$. In the present study, diabetes mellitus showed a 4.5 -fold increase in the risk of worsening functional capacity. This is because diabetes is accompanied by complications that include vascular, neuropathic and visual 
Table 2. Univariate logistic regression analysis of factors associated with functional disability in the elderly assisted by physical therapy.

\begin{tabular}{lcc}
\hline \multicolumn{1}{r}{ Variable } & Odds Ratio $(\mathbf{9 5 \%}$ CI $)$ & p-value \\
Age & $1.086(1.023-1.152)$ & 0.006 \\
Gender & &
\end{tabular}

\section{Female}

Male

$2.773(1.201-6.402)$

Caregiver

Yes

$2.833(0.975-8.232)$

0.017

General Health

Excellent
Good
Poor

Vision

Excellent

Good

Poor

Hear

Excellent

4.175 (1.301-13.395)

0.016

$12.349(2.464-61.888)$

0.002

0.056

$\begin{array}{lcc}\text { Yes } & 4.899(1.368-17.537) & 0.015 \\ \text { TUG } & 1.174(1.061-1.298) & 0.002 \\ \text { VAS } & 1.363(1.134-1.637) & 0.001\end{array}$

Good

Poor

Number of diseases

Comorbidities

3-4 diseases

$>5$ diseases

Hypertension

Yes

Stroke

Yes

Diabetes

Yes

Depression

Yes

Medications

Physical Activity

No

Falls

Yes

Dizziness

Yes

Cognition

Confused

Assistive devices

Lower Limbs pain Yes $4.119(1.406-12.062)$ 0.010

$2.265(0.756-6.783) \quad 0.144$

$4.872(0.756-19.339) \quad 0.024$

$1.569(1.149-2.143) \quad 0.005$

$3.677(1.401-9.652) \quad 0.008$

$6.655(2.003-22.106) \quad 0.002$

$1.860(0.802-4.314)$

0.148

0.056

0.024

$7.675(0.972-60.614)$

0.053

0.007

0.001

0.065

0.002

$7.059(0.890-55.972) \quad 0.064$

TUG=Time Up and Go; VAS=Visual Analogue Scale.
Table 3. Final model of multivariate logistic regression analysis of factors associated with functional disability in the elderly assisted by physical therapy.

\begin{tabular}{|c|c|c|c|}
\hline Variables & Odds Ratio & $(95 \% \mathrm{CI})$ & p-value \\
\hline \multicolumn{4}{|c|}{ Physical Activity } \\
\hline Yes & Reference & & \\
\hline No & 11.798 & $2.977-46.756$ & $>0.001$ \\
\hline \multicolumn{4}{|l|}{ Dizziness } \\
\hline Yes & 5.820 & & \\
\hline No & Reference & $1.110-30.499$ & 0.037 \\
\hline Medications & 1.646 & $1.207-2.245$ & 0.002 \\
\hline VAS & 1.719 & $1.277-2.313$ & $>0.001$ \\
\hline
\end{tabular}

VAS=Visual Analogue Scale.

pathologies and the risk of amputation, which in turn significantly affect the overall health of the elderly ${ }^{6}$.

Regarding depression and stroke, analysis of the data obtained revealed only a tendency towards the association with functional capacity. Depression affects physical independence through somatic symptoms, such as fatigue, and behavioral factors, as lack of motivation to perform tasks and social isolation ${ }^{19}$. Rosa et al. ${ }^{16}$ observed a 6.62 -fold increase in the likelihood of worsening functional capacity in patients with stroke. In a study by Pérès et al. ${ }^{19}$, the presence of sequelae due to stroke was associated with the progression of disability, but had no significant effect on functional recovery or mortality. This indicates that rehabilitation can be an effective way of maintaining or regaining functional autonomy in these patients ${ }^{19}$.

Another factor resulting from the high prevalence of diseases in the elderly is polypharmacy ${ }^{26}$. In agreement with this factor verified in the present study, the use of multiple medications has been associated with the risk of progression of disability ${ }^{19,27}$. According to the literature, the elderly population is more susceptible to adverse reactions and drug interactions due to the simultaneous use of numerous drugs and to modifications in pharmacokinetics induced by the physiological alterations associated with aging ${ }^{26}$.

In the present study, the characteristic that most determined a greater risk of disability was patient's self-reporting poor general health. These data corroborate reports by other authors ${ }^{6,28,29}$ regarding the assessment of general health as poor as a predictor of functional decline, with a range of 1.56-fold ${ }^{28}$ to 4.4-fold increase in risk ${ }^{29}$. According to Ayis et al. ${ }^{30}$, self-perception of general health as poor was considered a strong predictor for quick decline in mobility (OR 3.4). Subjective evaluation of health is considered to be a fast and easy instrument to administer and has proven to be as good as extensive data from laboratorial and clinical tests at predicting 
morbimortality ${ }^{31}$. Thus, the subjective perception of general health is important when assessing the elderly to determine dependency and because it is associated with motivation and patient adhesion to treatment. Since this sample consists of rehabilitation patients, it is important to verify whether any change in this perception occurred by the end of treatment.

Another variable associated with disability was dizziness, a symptom that is difficult to diagnose in the elderly given its diverse etiologies. Dizziness can have many causes, among which vestibular disorders, cardiovascular disease, psychiatric disease, neurological diseases and the side effects of some medications should be highlighted ${ }^{32}$. In outpatients, the prevalence of this symptom is 81 to $90 \%{ }^{33}$. In individuals aged over 65 year-old, dizziness is considered the most common symptom and over 75 years of age, its prevalence is $80 \%^{34}$. Knowledge of this complaint and identifying the causal factors can assist the therapist to establish effective measures to treat dizziness, such as vestibular rehabilitation.

In the present study, lack of physical activity was related to increased likelihood of elderly individuals becoming dependent. Stessman et al..$^{35}$ verified that a high level of physical activity was associated with the maintenance of functional independence over time, regardless of aging. The authors observed that in the elderly, physical activity could promote a protective effect against functional decline resulting in cardiovascular and immunological improvement, deceleration of sarcopenia and a reduction in adiposity.

A Brazilian population study verified that an increase in sedentary lifestyle occurs with advancing age, with prevalence rates of $31.8 \%$ in adults and $58 \%$ in the elderly ${ }^{9}$. Concerning the present sample, the high levels of sedentarism reported may be due to the difficulty experienced when attempting to perform regular exercise in the presence of other problems, such as pain. Pain assessed by VAS was strongly associated with disability, particularly when the pain occurred in the lower limbs. This complaint could undermine overall mobility and walking, creating further problems in relation to the practice of physical exercises among the elderly. Physical therapy is able to introduce exercises therapeutically in order to remedy these problems and, in light of its benefits, when treatment is completed, the practice should be continued. Such long-term care involves the referral of elderly individuals to services that promote special physical activity for this population so they can maintain functional capacity.

Among the limitations of the study, the lack of longitudinal follow-up and the non-application of specific tests to improve the detection of problems common to the elderly, such as sarcopenia, dementia and depression, should be highlighted. Another important factor is the diseases presented in the study were self-reported by the elderly individuals and not proven by medical diagnostic tests, thus their influence on functional capacity cannot be fully quantified.

Functional decline seems to be associated with a number of multidimensional factors that interact and determine capacity in the elderly, such that early identification of these factors could help prevent dependency ${ }^{29}$. However, even severe levels of disability can and should be treated. The Longitudinal Study on Ageing verified complete recovery of independence in ADL/IADL in 7\% of elderly males with severe disability and $3.5 \%$ of females ${ }^{36}$. These data reinforce the importance of rehabilitation for the elderly, even in the presence of complicating factors. Thus, it is important to train professionals in physical therapy so that they recognize what factors are associated with disability and that through adequate assessment, they can detect these and intervene.

\section{References}

1. Theme-Filha MM, Szwarcwald CL, Souza-Junior PRB. Socio-demographic characteristics, treatment coverage, and self-rated health of individuals who reported six chronic diseases in Brazil, 2003. Cad Saúde Pública. 2005;21(Suppl 1):43-53. http://dx.doi.org/10.1590/ S0102-311X200.500.0700006

2. Brach JS, VanSwearingen JM. Physical impairment and disability: relationship to performance of activities of daily living in community-dwelling older men. Phys Ther. 2002;82(8):752-61.

3. Richards S, Cristian A. The role of the physical therapist in the care of the older adult. Clin Geriatr Med. 2006;22(2):269-79; viii. PMID:16627078. http://dx.doi. org/10.1016/j.cger.2005.12.003

4. Boyd CM, Weiss CO, Halter J, Han KC, Ershler WB, Fried LP. Framework for evaluating disease severity measures in older adults with comorbidity. J Gerontol A Biol Sci Med Sci. 2007;62(3):286-95. PMID:17389726.

5. Giacomin KC, Peixoto SV, Uchoa E, Lima-Costa MF. A population-based study on factors associated with functional disability among older adults in the Great Metropolitan Belo Horizonte, Minas Gerais State, Brazil. Cad Saúde Pública. 2008;24(6):1260-70. http://dx.doi. org/10.1590/S0102-311X200.800.0600007

6. Alves LC, Leite IC, Machado CJ. Health profile of the elderly in Brazil: analysis of the 2003 National Household Sample Survey using the Grade of Membership method. Cad Saúde Pública 2008;24(3):535-546. http://dx.doi. org/10.1590/S0102-311X200.800.0300007

7. Erold CS, DeJong G. Determinants of utilization of physical rehabilitation services for person with chronic and disabling conditions: an exploratory study. Arch Phys Med Rehabil. 2008;89(1):114-120. http://dx.doi.org/10.1016/j. apmr.2007.08.122

8. Zhao M, Haley DR, Nolin JM, Dunning K, Wang J, Sun Q. Utilization, cost, payment, and patient satisfaction of rehabilitative services in Shandong, China. Health Policy. 2009;93(1):21-6. http://dx.doi.org/10.1016/j. healthpol.2009.05.011 
9. Siqueira FV, Facchini LA, Hallal PC. Epidemiology of physiotherapy utilization among adults and elderly. Rev Saúde Pública. 2005;39(4):662-8. http://dx.doi. org/10.1590/S0034.891.0200500.040.0022

10. Moretto LC, Longo GZ, Boing AF, Arruda MP. Prevalence of the use of physical therapy services among the urban adult population of Lages, Santa Catarina. Rev Bras Fisioter. 2009;13(2):130-5. http://dx.doi.org/10.1590/ S1413.355.5200900.500.0023

11. Podsiadlo D, Richardson S. The Timed "Up \& GO": a test of basic functional mobility for frail elderly persons. J Am Geriatr Soc .1991;39(2):142-8. PMID:1991946

12. Shumway-Cook A, Brawer S, Woollacott M. Predicting the probability for falls in community-dwelling older adults using the Time Up \& Go test. Phys Ther. 2000;10(9):896-903. PMID:10960937

13. Duke University Center For The Study Of Aging And Human Development. Multidimensional Functional Assessment: The Oars Methodology. Duke: Durhan; 1978.

14. Blay SL, Ramos LR, Mari JdeJ. Validity of a Brazilian version of the Older Americans Resources and Services (OARS) mental health screening questionnaire. J Am Geriatr Soc. 1988;36(8):687-92. PMID:3403873.

15. Rodrigues RMC. Validation of the European Portuguese version of the Older Americans Resources and Services instrument. Rev Panam Salud Pública. 2008;23:109-15. http://dx.doi.org/10.1590/S1020.498.9200800.020.0006

16. Rosa TEC, Benício MHD, Latorre MRDO, Ramos LR. Determinant factors of functional status among the elderly. Rev Saúde Pública. 2003;37(1):40-8. http://dx.doi. org/10.1590/S0034.891.0200300.010.0008

17. Wewers ME, Lowe NK. A critical review of visual analogue scales in the measurement of clinical phenomena. Res Nurs Health. 1990;13(4):227-36. http://dx.doi. org/10.1002/nur.477.013.0405

18. Calil AM, Pimenta CAM. Pain intensity of pain and adequacy of analgesia. Rev Latinoam Enferm. 2005;13(5):692-9. http://dx.doi.org/10.1590/ S0104.116.9200500.050.0013

19. Pérès K, Verret C, Alioum A, Barberger-Gateau P. The disablement process: factors associated with progression of disability and recovery in French elderly people. Disabil Rehabil. 2005;27(5):263-76. PMID:16025753.

20. Hairi NN, Bulgiba A, Cumming RG, Naganathan V, Mudla I. Prevalence and correlates of physical disability and functional limitation among community dwelling older people in rural Malaysia, a middle income country. BMC Public Health. 2010;10:492. PMCID: PMC2933720. http://dx.doi.org/10.1186/1471-2458-10-492

21. Camargos MCS, Perpétuo IHO, Machado CJ. Life expectancy with functional disability in elderly persons in São Paulo, Brazil. Rev Panam Salud Publica. 2005;17(5-6):379-86. PMID:16053648. http://dx.doi. org/10.1590/S1020.498.9200500.050.0010

22. Parahyba MI, Simões CCS. Disability prevalence among the elderly in Brazil. Ciênc Saúde Coletiva. 2006;11(4):967-74. http://dx.doi.org/10.1590/ S1413.812.3200600.040.0018

23. Siebens HC. Musculoskeletal problems as comorbidities. Am J Phys Med Rehabil. 2007;86(1 Suppl):69-78. PMID: 7370373. http://dx.doi.org/10.1097/ PHM.0b013e31802ba581

24. Cruise CM, Lee MHM. Delivery of rehabilitation services to people aging with a disability. Phys Med Rehabil Clin N Am. 2005;16(1):267-84. PMID: 15561555.
25. Chaudhry SI, McAvay G, Ning Y, Allore HG, Newman AB, Gill TM. Geriatric impairments and disability: the cardiovascular health study. J Am Geriatr Soc. 2010;58(9):1686-92. PMID:20863328, http://dx.doi. org/10.1111/j.1532-5415.2010.03022.x

26. Loyola Filho AI, Uchoa E, Firmo JOA, Lima-Costa MF. A population-based study on use of medications by elderly Brazilians: the Bambuí Health and Aging Study (BHAS). Cad Saúde Pública. 2005;21(2):545-53. http://dx.doi. org/10.1590/S0102-311X200.500.0200021

27. Hanlon JYT, Fillenbaum GG, Kuchibhatla M, Artz MB, Boult C, Gross Cr, et al. Impact of inappropriate drug use on mortality and functional status in representative community dwelling elders. Med Care. 2002;40(2):166-76. PMID: 11802089.

28. Lee Y. The predictive value of self-assessed general, physical, and mental health on functional decline and mortality in older adults. J Epidemiol Community Health. 2000;54(2):123-9. PMCID: PMC1731623. http://dx.doi. org/10.1136/jech.54.2.123

29. Nogueira SL, Ribeiro RCL, Rosado LEFPL, Fransceschini SCC, Ribeiro AQ, Pereira ET. Determinant factors of functional status among the oldest old. Rev Bras Fisioter. 2010;14(4):322-9. http://dx.doi.org/10.1590/ S1413.355.5201000.500.0019

30. Ayis S, Gooberman-Hill R, Bowling A, Ebrahim S. Predicting catastrophic decline in mobility among older people. Age Ageing. 2006;35(4):382-7. PMID: 16638760

31. Quesnel-Vallee A. Self-rated health: caught in the crossfire of the quest for 'true' health? Int J Epidemiol. 2007;36(6):1161-4. PMID: 18056123. http://dx.doi. org/10.1093/ije/dym236

32. Maarsingh OR, Dros J, Schelleviss FG, van Weert HC, van der Windt DA, Ter Riet G, et al. Causes of persistent dizziness in elderly patientes in primary care. Ann Fam Med. 2010;8:196-205. PMID:20458102. http://dx.doi. org/10.1370/afm.1116

33. Fanelli RRG, Barreto Filho ACP. Avaliação multidisciplinar em idoso com tontura. Conscientiae Saúde. 2002;1:31-3.

34. Ruwer SL, Rossi AG, Simon LF. Balance in the elderly. Rev Bras Otorrinlaringol. 2005;71(3):298-303. http:// dx.doi.org/10.1590/S0034.729.9200500.030.0006

35. Stessman J, Hammerman-Rozenberg R, Cohen A, Ein-Mor E, Jacobs JM. Physical activity, function, and longevity among the very old. Arch Intern Med 2009;169:1476-83. PMID:19752405.

36. Mor V, Wilcox V, Rakowski W, Hiris J. Functional transitions among the elderly: patterns, predictors, and related hospital use. Am J Public Health. 1994;84(8):1274-80. PMID: 8059885.

\section{Correspondence}

\section{Ana Letícia Sarkis Rossi}

Av. Paulo de Arruda Correia da Silva, 246

Recreio dos Bandeirantes II

CEP 13575-842, São Carlos, SP, Brasil

e-mail: leticiasarkis@hotmail.com 